\title{
A Different Experience in a Different Moment? Teachers' Social Media Use Before and During the COVID-19 Pandemic
}

\author{
Stephen J. Aguilar ${ }^{1}$ \\ Joshua Rosenberg $^{2}$ \\ Spencer P. Greenhalgh ${ }^{3}$ \\ Tim Fütterer ${ }^{4}$ \\ Alex Lishinski ${ }^{2}$ \\ Christian Fischer ${ }^{4}$
}

${ }^{1}$ University of Southern California Rossier School of Education

${ }^{2}$ University of Kentucky, School of Information Science

${ }^{3}$ University of Tennessee, Theory and Practice in Teacher Education

${ }^{4}$ University of Tübingen, Hector Research Institute of Education Sciences and Psychology

Corresponding Author:

Stephen J. Aguilar

aguilars@usc.edu 


\begin{abstract}
Teachers participate in professional development activities to enhance their pedagogical knowledge and share best practices — and the increasing role of technologies in education, including social media, is shifting how this professional development occurs. The COVID-19 pandemic provided an opportunity to further consider the role of social media for professional learning. Using intensive longitudinal methods, we investigated 14 teachers' use of social media both before and during the pandemic ( $n=386$ total responses). We found some general patterns in social media platforms uptake and their purposes, but teachers' use of social media was largely idiosyncratic. Also, teachers demonstrated notable shifts in social media use after the pandemic started; multi-level models indicated that teachers were more likely to use social media to connect and share, especially, compared to before the pandemic. Higher levels of COVIDrelated stress were also associated with more use of social media for emotional and community benefits.
\end{abstract}

Keywords: Online Communities, Informal Teacher Learning, Professional Learning Networks, COVID-19, Social Media 


\section{A Different Experience in a Different Moment? Teachers' Social Media Use Before and During the COVID-19 Pandemic}

\section{Introduction}

Teachers participate in professional development activities throughout their careers to enhance their knowledge about teaching and to share best practices (Borko et al., 2010; DarlingHammond et al., 2017; Fischer et al., 2018). Given the changing needs of students and shifting policies that influence the curriculum teachers enact, ensuring that there are sufficient opportunities to participate in meaningful professional development has been shown to be a central strategy to promote an effective and responsive education system (Borko et al., 2010; Dede et al., 2008). Although professional development is often a formal process organized by schools, districts, and other institutions, teachers have also long engaged in informal learning that supports their professional practice (Dede \& Eisenkraft, 2016; Kyndt et al., 2016).

The internet has provided new opportunities for this informal learning (e.g., Trust et al., 2016), and over the past decade, teachers have taken particular interest in teachers' professional use of social media (Greenhow et al., 2020). Inherently operating at a distance, social media services provide multiple platforms for teachers to engage with each other to provide instructional, material, or emotional support. Social media is nimble and able to facilitate the sharing of information quickly, at scale, and across geographic boundaries. Teachers have reported using a wide range of social media platforms (see Greenhow et al., 2020) for a wide range of purposes (Carpenter \& Krutka, 2014, 2015).

The COVID-19 pandemic has provided an important opportunity to further consider teachers' use of social media for professional learning. The pandemic created a need for additional professional development to support the rapid deployment of emergency remote 
learning measures, especially considering the greater need for that support in under resourced areas (Aguilar et al., 2020). Yet, despite the scholarly community's rapid response to the lack of existing professional development (e.g., Aguilar, 2020a; Aguilar, 2020b; Greenhow \& Chapman, 2020; Hickey et al., 2020; MacMahon et al., 2020), the pandemic disrupted established routines and contexts for professional development where such resources could be used. Social media, however, has been shown to be useful for "just-in-time" learning during a crisis (e.g., Greenhalgh \& Koehler, 2017), so it is unsurprising that many did so during the pandemic (e.g., Fütterer et al., 2021; Greenhow et al., in press; Trust et al., 2020). We consider the details of teachers' use of social media prior to and during the pandemic to lend insight into their COVID19 experiences while also offering answering broader questions focused on how teachers make decisions about their social media use.

\section{Purpose and Research Questions}

The COVID-19 pandemic represents a particular, semi-universal need for teachers' professional learning. As teachers were not able to turn to in-person professional development to adapt to new realities, and as school closures constrained informal exchange with colleagues from one's own school, many teachers turned to online social media instead. Hashtag-based Twitter communities like \#RemoteLearning or \#RemoteTeaching in the U.S. context (Trust et al., 2020) or \#Twitterlehrerzimmer (German for "Twitter Teachers' Lounge") in the German context (Fütterer et al., 2021) were also used by many teachers to respond to their immediate need for professional development. Similarly, Greenhow and colleagues (in press) have documented how activity in the longstanding \#Edchat hashtag has changed in response to the pandemic.

Our investigation's primary aim is focused on capturing similar patterns across social media platforms and over time. Specifically, we capture which social media platforms teachers 
used for professional development and how often they did so over the 2019-2020 academic year. We focus on the period of January 2020 to June 2020, thus encompassing social media use prior to the pandemic and during the deployment of emergency distance learning measures. We note that pandemic-related questions were added to our project once it became clear that uses of social media might shift as a result of emergency distance learning. We operationalize our aims through the following research questions (RQs):

1. What social media platforms do teachers use — and for what purposes?

2. How, if at all, did teachers' social media use change in response to the COVID-19 pandemic?

3. How, if at all, did stress moderate changes in teachers' social media use during the COVID-19 pandemic?

\section{Background}

\section{Informal Teacher Learning and Online Communities}

Learning processes in professional development activities can range from formal to informal contexts (Dede \& Eisenkraft, 2016; Kyndt et al., 2016). More formal learning is often structured with respect to learning goals, time schedules and support system. In contrast, informal learning is characterized by lower degrees of planning, organizing, and autonomy, which also allow for closer alignment with teachers' individual needs (Bruguera et al., 2019; Richter et al., 2011, Kyndt et al., 2016). Therefore, a key characteristic of informal learning is that self-directed and self-regulated learning are encouraged. Learners take an active role by setting their own learning objectives and deciding for themselves when to use which resources for learning (Kleiman \& Wolf, 2016). Informal learning is most often realized through activities like collaboration with colleagues, sharing materials and resources or learning from others, 
which dominate teachers' workplace learning (Kyndt et al., 2016). Because activities like collaboration or exchange of ideas constitute informal learning, proximity to colleagues is crucial to facilitate informal encounters or discussions (Kyndt et al., 2016).

Online communities have the potential to create this spatial and temporal proximity, while offering opportunities for teachers to learn, share educational resources, and communicate with their peers despite geographic distance (Carpenter \& Krutka, 2014, 2015; Dede et al., 2009). In general, participation in online communities has become a common activity of many teachers (Macià \& García, 2016). For instance, teachers create and use educational digital archives to create and share educational resources online to support their instruction (Recker et al., 2005, 2007). Some early studies have shown positive effects of teachers' participation in online communities on teacher knowledge, teaching practices, and student performance (e.g., Fishman et al., 2014; Frumin et al., 2018). Notably, social media platforms provide prime examples of digital spaces for teachers to engage in collaborative participation and interaction to form online communities that can lead to informal teacher learning (Bruguera et al., 2019;

Greenhow et al., 2020).

\section{Teachers Use of Social Media Platforms}

Teachers' use of social media platforms for informal professional development has been an established phenomenon for over a decade (Greenhow et al., 2020). This rise of social media platforms among teachers is often attributed to their potential for self-organization, communication, and self-sustaining communities which are important features for sustainable and active communities (Kraut \& Resnick, 2012; Liu et al., 2016). Teachers use a variety of different social media platforms and each platform has its own specific affordances and 
challenges for informal learning (Bruguera et al., 2019; Greenwood et al., 2016). We describe the commonly used social media platforms for teachers in the U.S. below.

\section{Facebook}

Teachers primarily use Facebook to stay informed (Hu et al., 2018) and to network and exchange ideas on specific topics related to their professional practice. However, teachers' decisions with regard to the scope of private information they disclose (i.e., decisions on privacy settings) may be challenging. When teachers disclose private information about themselves (e.g., messages from family members), this can have a positive effect on student-teacher relationships but also lead to a decrease in teachers' credibility (Mazer et al., 2007). Early career teachers have also been shown to use private groups to get social support from colleagues (especially from teachers they know already outside of Facebook), particularly when dealing with challenging situations (Mercieca \& Kelly, 2018).

\section{Twitter}

Twitter is a microblogging platform. "Tweets," limited to 280 Unicode characters, or audio/video messages, can be linked to specific topics using hashtags (\#) or specific users (@). Twitter has been shown to enable informal learning processes among teachers due to the breadth and depth of available information, the dynamic display of new information, and the limited time commitments for individual posts (for summaries, see Fischer et al., 2019; Staudt Willet, 2019). In addition, teachers use Twitter for many different purposes, e.g., sharing resources, collaboration with other colleagues, networking, emotional support, combat isolation (Carpenter \& Krutka, 2014, 2015; Rosenberg et al., 2020; Staudt Willet, 2019).

Initial evidence suggests that teacher activities on Twitter can meet criteria for highquality PD such as collective participation and duration thresholds as a form of just-in-time 
professional development activity (Greenhalgh \& Koehler, 2017; Fischer et al., 2019). Teachers using Twitter are typically active on a daily basis to connect with colleagues with the same interests (Carpenter \& Krutka, 2014; Fischer et al., 2019; Visser et al., 2014). Notably, teachers rarely use Twitter to design their teaching lessons or to interact with students (Carpenter \& Krutka, 2014; Visser et al., 2014).

\section{Pinterest}

Pinterest is an online platform to discover, save and share information (e.g., webpages, images, or videos, which are called "ideas" or "pins") in the form of pin boards on specific topics (e.g., lesson plans). Users can save new pins (linked from websites or uploaded by the user or by saving from outside of Pinterest) to individual boards or save pins from other users' boards (called repinning), follow other users or specific boards and structure boards by creating different sections. Compared to Twitter and Facebook, the research base on Pinterest use in the educational context is more nascent (Greenhow \& Askari, 2017; Greenhow et al., 2020; Hu et al., 2018; Carpenter et al., 2018). Still, recent work suggests that teachers use Pinterest predominantly for accessing educational resources (Carpenter et al., 2018; Hu et al., 2018).

\section{Instagram}

Instagram is an image-focused social media platform that is owned by Facebook. Carpenter, Morrison, and colleagues (2020) report that teachers using Instagram "overwhelmingly indicated they had originally started using Instagram for non-professional purposes" (p. 5); yet, over $90 \%$ of respondents to their survey reported checking Instagram for professional purposes at least once a day, and a majority of teachers identified learning from other teachers as a "major reason" for their use of the platform. Shelton and colleagues (2020) specifically consider the presence on Instagram of edu-influencers: "individuals who have 
achieved microcelebrity status... by promoting certain education-related products, philosophies, or practices" (p. 530). They found that the edu-influencers they studied shared promotional content and motivational content, solicited engagement, and advocated for particular classroom approaches.

\section{Other common platforms}

While the platforms listed above have been identified as playing an important role in teachers' informal learning, it should be noted that teachers may also use other platforms for professional purposes. For example, Staudt Willet and Carpenter $(2020,2021)$ have noted the presence of education-related subreddits (i.e., topical discussion boards) with distinct patterns of activity on the popular website Reddit. Subreddits have been shown to serve as a "conversational space" more focused on teacher interaction and the other as a "bulletin board space" that was broadly interested in educational topics (Staudt Willet \& Carpenter, 2021). Carpenter and Green (2017) have noted teachers' use of the multimodal instant messaging platform Voxer to engage with peers and communities, and teachers have long used blogs to share about their work and experience (e.g., Greene, 2017).

\section{Teacher Needs and Professional Learning Networks}

A common theoretical approach to frame social-media-based teacher professional development is the Professional Learning Network (PLNs; Bruguera et al., 2019; Greenhow et al., 2020). Although some equate PLNs with particular online community (Flanigan, 2011), this

study applies a broader perspective that views a teacher's PLN as a personalized comprehensive system of interactions with the multiple communities on the variety of social media platforms a teacher participates in (Trust et al., 2016). The specifics of a PLN are driven by an individual teacher's needs. Therefore, the goal of an online community should be driven in a democratic 
process by the needs of the individual teachers (Liu et al., 2016). Indeed, teachers engage in PLNs for many different reasons (Carpenter, Tani et al., 2020, Rosenberg et al., 2020). For example, teachers may aim to find and/or share professional knowledge and educational resources, or to receive emotional support by colleagues (Carpenter \& Krutka, 2014, 2015; Fütterer et al., 2021; Hur \& Brush, 2009; Trust et al., 2016; Visser et al., 2014).

As "one size does not fit all" (Liu et al., 2016, p. 20), each teacher determines their own set of social media platforms to build a sustained PLN (Trust et al., 2016). Teachers vary not only in the composition of different social media platforms depending on their purpose but also in how they use each platform. Even on the same social media platform, different spaces are characterized by different patterns of activity. For example, different Twitter hashtags have different patterns of activity (e.g., Carpenter, Tani et al., 2020; Greenhalgh, 2021), chat and nonchat activity can look different within the same hashtag (e.g., Carpenter, Tani et al., 2020; Greenhalgh et al., 2020), and the activity of users varies from individual to individual (e.g., Rosenberg et al., 2016). In addition, teachers have different approaches to how they use social media. Some people (lurkers or info-consumers) use social media platforms more passively like watching others' posts (called lurkers or info-consumer) whereas others (called posters, infonetworkers, self-seeking contributors, or vocationalists) use social media platforms more actively, such as sharing resources with others (Frumin et al., 2018; Prestridge, 2019; Speily et al., 2020). To summarize, it can be assumed that each teacher's PLN looks different depending on their individual needs.

\section{Methodology}

To answer our research questions, we collected data using intensive longitudinal methods, a research methodology that involves asking participants about their experiences at the 
time or near to the time they are signaled to respond to short surveys (Bolger \& Laurenceau, 2013). To do so, we designed a novel system for collecting data via intensive longitudinal methods, [name omitted for peer review].

\section{Participants}

We recruited participants via social media and through professional networks and narrowed our focus to mathematics teachers who use social media to assist their planning or teaching. We received 19 valid responses to this initial survey, which included demographic questions and questions about which social media platforms they used. From the initial pool of valid responses, we 14 participants agreed to participate in the primary study.

The majority of teachers in our sample were White $(76.9 \% ; n=10)$. Two $(15.3 \%)$ were Asian and one (7.6\%) was African American. (One participant chose not to disclose their racial/ethnic background). Ten (76.9\%) participants identified as female, and $3(21.4 \%)$ as male, with one person choosing not to indicate their gender. Participant's ages ranged from 24-62, with a mean age of $39.1(S D=10.4)$. The percentage of teachers' students receiving free and reducedprice lunches ranged from less than $10 \%$ to more than $75 \%$. They taught in 12 different states and were from all four census regions of the country. Teachers had varied amounts of teaching experience, ranging from 1-35 years, with a mean of 11.5 years $(S D=10.3)$. Grade levels taught ranged from Kindergarten-8th grade, with 5th, 3rd, and 1st grades being the most common.

Before the study started, teachers reported using the following services (see Table 1) and, through an open text response option, the platform Blogger. We used these to determine which platforms we focused on in this study, namely, Twitter, Facebook, Pinterest, Instagram, LinkedIn, Reddit, and Blogs, but not Voxer.

<Insert Table 1 about here> 


\section{Data Collection Procedure}

We developed and implemented a novel system for collecting self-reported information on teachers' social media use. [Name omitted for peer review] is a Python-based application that uses the Flask web application framework. Flask uses the Application Programming Interface for Twilio (a web-based application for sending and receiving text messages) to send out text messages. In this way, [name omitted for peer review] made it possible to carry out a study utilizing intensive longitudinal methods entirely through text messages.

After asking participants for their phone numbers in the initial survey, we sent surveys to them every Monday and Friday via text message. These surveys were designed to be completed quickly and in such a way that participants could effectively recall how they used social media for teaching. Initially, we sent eight surveys to teachers from Monday, 31 Jan 2020 - Friday, 24 Feb 2020, each Monday and Friday. Then, in response to the changing needs brought on by distance learning, we extended our data collection with an additional 22 surveys (for a total of 30), from Friday, 17 Apr 2020 - Monday, 29 June 2020. As a result, we considered surveys 1-8 to be before the pandemic, and those from 9-30 to be during the pandemic. We found that surveys were completed, on average, with a median time of 1.83 minutes $^{1}$. On average participants responded to 27.6 of the 30 possible surveys (91.9\%), which is a high response rate for a study using intensive longitudinal methods (Hektner et al., 2007). We collected a total of 386 responses to surveys.

\footnotetext{
${ }^{1} 50$ responses took longer than five minutes; 29 responses took longer than ten minutes; and 20 responses took longer than one hour. The responses that took longer than one hour were likely due to participants opening the survey in a browser, but not completing it immediately. We used the median instead of mean to remove the undue influence of these on our calculation of the response rate (though we did not remove these from the other analyses).
} 


\section{Measures}

In line with previous work on professional development (e.g., Carpenter \& Krutka, 2014, 2015; Prestridge, 2019), our instrument focused on capturing how teachers used social media for professional purposes, described below.

\section{Social media tool selection}

Upon opening the survey, teachers were asked: "Which tools did you use this work week (M-F)? (Please check all that apply).” The tools included Facebook, Instagram, LinkedIn, Pinterest, Reddit, Twitter, teacher blogs, "other" (with a field to record responses), and "none."

\section{Social media tool use}

Using carry forward logic, teachers answered follow-up questions for the platforms they selected. We identified a list of purposes on the basis of prior research (Greenhalgh et al., 2016; Carpenter \& Krutka, 2014; 2015) as well as our experiences using and studying social media. In total, we identified 9 purposes:

1. Finding materials for class

2. Sharing my materials

3. Sharing my experiences

4. Learning about or reviewing curricular content

5. Learning about or reviewing teaching strategies

6. Connecting with other educators

7. Seeking emotional support

8. Following or engaging with specific organizations

9. Following or engaging with specific websites 
To facilitate analyses, we combined purposes $2-3,4-5,6-7$, and $8-9$ on the basis of their similarity. This left us with five distinct purposes: (a) Finding; (b) Sharing; (c) Learning; (d) Connecting; and (e) Following.

\section{COVID-19 and technology-related stress}

For the 22 surveys administered during the COVID-19 pandemic, we asked teachers how often "parenting issues, family relationships, friendships, mental health problems, physical health problems, Coronavirus related to yourself, Coronavirus related to your family, and Coronavirus and your larger community/country" caused stress over the past 7 days. Items were measured using a 7-point Likert-type scale with "never" and "every day” as anchors. Technology-related stress was similarly measured; teachers rated how often "Videoconferencing software for work, Videoconferencing software for my children, Computer Hardware (e.g., computer, laptop), Learning management software (e.g., Canvas, Blackboard), Email, and Social Media” caused stress over the previous week. Both the purposes and stress measure items were posed to participants in each survey with respect to their experience over the period of time between the last and the present survey.

\section{Data Analysis}

For RQ1, we described what social media platforms teachers reported using through the text message-based surveys as well as the purposes for which they used them. Then, we used mixed effects models (Raudenbush \& Bryk, 2002; West et al., 2014) to understand how the frequency of the five purposes changed from before the pandemic to during the pandemic (RQ2) and how teachers' stress during the pandemic related to their use of social media for any of the five purposes (RQ3). 
For the analysis of the change in teachers use of social media after the COVID-19 pandemic (RQ2), we regressed a dichotomous variable indicating whether the response was collected before or during COVID-19 (the sole independent variable) upon a dichotomous variable indicating whether a teacher reported using any social media platform for a specific purpose at that time point. Accordingly, we specified a binomial outcome distribution. The grouping variable was an identifier for the teacher, so the model is a generalized linear multilevel model. For these analyses and the analyses for RQ3, responses were considered to be grouped within teachers (e.g., up to 30 responses were considered to be grouped within each of the 14 teachers; $N=386$ total survey responses). Thus, while our statistical power at the teacher level was relatively low, our power at the individual response level was relatively high. The equation for this model is presented below for response $i$ for teacher $j$ :

$$
\begin{gathered}
\log \left[\frac{P(\text { Use }=1)}{1-P(\text { Use }=1)}\right]=\beta_{0}+\beta_{1}\left({\text { Survey } \left.\text { Period }_{\text {COVID }}\right)+\epsilon_{i}}_{\beta_{0}=\beta_{00}+\alpha_{j}}\right.
\end{gathered}
$$

For the analysis of the effect of teachers' COVID-related stress levels on their social media use (for RQ3), we filtered the dataset to include only the responses associated with the COVID-19 data collection period and regressed a continuous composite measure of teachers' stress (that served as the sole independent variable) upon the same dichotomous variable used in the RQ2 analysis. Accordingly, this model is also a generalized linear multilevel model with a binomial outcome distribution, again with the teacher identifier specified for the grouping variable, as in equation 2 for response $i$ for teacher $j$, using only responses collected during the COVID-19 pandemic: 


$$
\begin{gathered}
\log \left[\frac{P(\text { Use }=1)}{1-P(\text { Use }=1)}\right]= \\
\beta_{0}+\beta_{1}(\text { Stress related to COVID })+\epsilon_{i} \\
\beta_{0}=\beta_{00}+\alpha_{j}
\end{gathered}
$$

We estimated the models using the lme4 R package (Bates et al., 2014) and checked their assumptions using the performance $\mathrm{R}$ package (Lüdecke et al., 2020). For both, we first estimated a variance components model, one with only the group term included (i.e., without the fixed effects term included) in order to estimate the intra-class correlation, which indicates how much of the variation is attributable to the grouping factor; this was found to be 0.592 for the analyses for RQ2, and 0.610 for the analyses for RQ3 (using the same dependent variable but only the responses collected during the COVID-19 period). To interpret the models, we focused on the regression coefficient $(B)$ (for RQ2: of the survey period; for RQ3: the composite variable for stress related to COVID-19), which we exponentiated to be an Incident Rate Ratio (IRR; and its standard error $(S E)$-also exponentiated), and the $p$-value of these coefficients. Because of difficulties in interpretation related to IRRs — and greater difficulties related to the estimate in log-odds units - we also calculated average marginal effects (AVEs). An AVE is the value (in the original units of the dependent variables) of the effect of a one-unit change in the independent variable upon the dependent variable (Leeper, 2018).

\section{Results}

\section{General Uses and Purposes of Social Media (RQ1)}

We found that teachers' professional uses of social media are diverse and highly specific to each teacher. Figure 1 visually represents the frequency with which each of the participants in our study used each of five social media platforms for each of five distinct purposes. 
$<$ Figure 1 about here>

As evidenced by the different patterns within the different boxes, teachers showed a wide range of different uses of platforms for different purposes. For example, as compared to their colleagues, Participant 11 rarely used social media at all; however, when they intended to share, they typically used Facebook, and when they intended to follow, they typically relied on blogs (with Pinterest serving an auxiliary function for both purposes). In contrast, Participant 7 used social media more frequently, relying heavily on blogs for all five purposes and frequently using Instagram for targeted purposes (i.e., sharing and connecting).

Although it is important to recognize the idiosyncratic nature of teachers' social media use, there are also general trends of platform use that merit attention (see Table 2). For example, the teachers in our sample prize Facebook and blogs above other social media platforms; however, there are no general purposes of social media use that stand out. Furthermore, teachers appear to associate particular platforms with particular purposes. That is, while Facebook and blogs are both used widely, Facebook appears to be used more for sharing and connecting while blogs are used more for finding and learning. Pinterest also stands out as a largely single-purpose platform (i.e., for finding).

<Insert Table 2 about here>

\section{Changes in Social Media Use Due to Pandemic (RQ2)}

Table 3 indicates differences in teachers' use of social media before and during the COVID-19 pandemic. In general, teachers appeared to more frequently engage in learning and following - and especially connecting and sharing — after the pandemic began. The average marginal effect (AME) for sharing indicates that the likelihood of teachers' sharing at any one time point was around 42 percentage points higher during the pandemic, and the likelihood of 
teachers' connecting appears to be 39 percentage points higher. There was no significant difference in teachers' rates of finding before or during the pandemic.

<Insert Table 3 about here>

\section{Moderation of Social Media Use Due to Stress (RQ3)}

Considering teachers' stress levels allows further insight into how their pandemic experience may have affected their professional uses of social media. Table 4 reports on the effect of only COVID-related stress levels (the effect of other measures of stress can be seen in the Appendix). When teachers specifically experienced higher levels of stress related to COVID19, they were less likely to use social media for sharing and connecting — purposes that have less to do with utilitarian benefits and more to do with emotional and community benefits of social media for teachers. The AMEs here indicate the effect of a one-SD change in stress (which was measured using a 1-7 scale). For example, a one-unit change in stress is associated with an AME of -0.08 , indicating an approximately 8 percentage point decrease in teachers' likelihood of using social media to connect when they experience a one-unit increase in COVID-19-related stress. The effect on learning was approaching statistical significance $(p=.068)$ in the opposite direction: teachers' likelihood of using social media for learning was 7 percentage points higher for every one-SD increase in stress they experienced.

<Insert Table 4 about here>

\section{Discussion}

Previous research suggests that teachers' use of social media for professional learning is individualized and diverse. That is, "one size does not fit all" (Liu et al., 2016, p. 20). For example, individual teachers (should) determine which social media platforms (and other resources) they incorporate into their PLNs based on their own needs (Krutka et al., 2017; Trust 
et al., 2016) — not least because different platforms have different affordances and constraints (Staudt Willet, 2019; Staudt Willet \& Carpenter, 2020), and social media-based communities demonstrate different patterns of activity (Carpenter, Tani, et al., 2020; Greenhalgh, 2021). Furthermore, teachers have reported and demonstrated a range of different purposes for their use of social media (e.g., Carpenter \& Krutka, 2014, 2015; Greenhalgh et al., 2016), as well as different rates of participation in social media communities (Rosenberg et al., 2016).

The present study furthers our understanding of this individualization and diversity in teacher learning on social media. Our collection of data both before and during the COVID-19 pandemic allows a unique perspective on how teachers change their use of social media in response to changes in the context around them. The combination of these two factors allows for poignant illustrations of the idiosyncratic nature of teachers' social media use. For example, Figure 1 demonstrates the sheer variety that characterizes our sample's use of social media over time. Similarly, the grouping factors of our analyses for RQ2 and RQ3 indicate that around 60\% of the effects measured in each analysis are attributable to differences between individuals (rather than just observations). This suggests considerable idiosyncrasy; as teacher educators (and others) continue to introduce pre- and in-service teachers to social media (e.g., Greenhalgh et al., 2016; Gurjar, 2019), they should be careful not to prescribe particular platforms or purposes but rather invite educators to consider which uses might best respond to their own needs (see Krutka et al., 2017). The results also highlight two patterns that add important clarification to this initial finding of individualization and diversity. One the one hand, our results suggest that individualization of teachers' social media use is largely due to teachers' sensitivity to a number of contextual issues. On the other hand, our results suggest that teachers have particular needs that have arisen from the COVID-19 pandemic. 
Also, this study makes a methodological contribution for studying teachers' professional learning. The use of intensive longitudinal methods allowed for a highly granular, intimate understanding of how individual teachers used individual platforms for individual purposes. In this way, this study builds on past research using intensive longitudinal methods, including the experience sampling method (Hektner et al., 2007), to study teachers' diversity and individualization as well as variation in teachers' experience in a more granular and also ecologically valid way (Reis, 2011). Utilizing multi-level models also us to account for how teachers' responses could be considered to be nested within teachers (just as repeated measures from students are often modeled as such; Raudenbush \& Bryk, 2002). In this way, we were able to compare the purposes for which teachers use social media before and during an extraordinary disruption, doing so based not upon retrospective accounts, but brief surveys twice per week over more than one dozen weeks - which are likely to be more accurate and therefore can be used as more valid measure than retrospective accounts (Schwarz, 2011). While intensive longitudinal methods can be administered through a variety of platforms, including mobile applications, beepers, and even pencil-and-paper surveys (Inkinen et al., 2020; Schmidt et al., 2018; Xie et al., 2019), their use is less-established within teacher education research. Thus, our study provides a proof of concept to use such intensive longitudinal methods to study individualization and diversity in teachers' planning, practice, and professional learning.

\section{Teachers' Sensitivity to Context}

As previously noted, teachers in our sample showed considerable idiosyncrasy in their use of social media during the timeframe of this study. However, further consideration of these patterns of individualization and diversity lends further insight into the ways that teachers are sensitive to several contextual factors in their choices of social media. For example, teachers' 
general preferences for particular platforms (among this sample, Facebook and blogs) suggests either attention to the particular affordances of those platforms for learning (e.g., Staudt Willet, 2019; Staudt Willet \& Carpenter, 2020) or the ways those platforms converge with the other ways they already use social media (e.g., Carpenter, Morrison, et al., 2020; Greenhalgh et al., 2016). In either case, this suggests a sensitivity to one's own preferences and needs that corresponds with scholarship on effective use of Professional Learning Networks.

Teachers' sensitivity to the advantages and disadvantages of different social media platforms is complemented by their sensitivity to different purposes of professional learning. Although Table 2 suggests that in aggregate, teachers in our sample engaged in different purposes of social media-supported professional learning at similar levels, Figure 1 adds further nuance. Some teachers clearly prioritize some purposes over others, including different levels of consuming media (like lurkers; Romero-Hall et al., 2020) versus producing media (like eduinfluencers; Shelton et al., 2020). Not only does this suggest teachers' further attention to their personal needs, but Figure 1 illustrates of how teachers use platforms for particular needs demonstrating that certain platforms are better- (or worse-) suited for particular needs than others.

Finally, the clear changes in teachers' social media use in response to the COVID-19 pandemic underlines even more sensitivity to context. Our data suggests that teachers in our sample intentionally changed their activity on social media in response to the pandemic. The combination of these three observations suggests considerable reflection and deliberation on the part of teachers as they use social media. 


\section{Teachers' Pandemic Needs}

Changes in teachers' social media use in response to the pandemic lends insight into the particular needs that they were expressing at that time. Teachers' use of social media is often framed primarily in terms of professional learning (and often as a response to inadequate professional development; e.g., Carpenter \& Krutka, 2015), so it is unsurprising that teachers' likelihood of following and learning through social media was higher during the pandemic than prior to it. Most teachers had much to learn in response to emergency remote teaching, and normal avenues of professional development were as disrupted by the pandemic as were their classrooms.

However, the increased likelihood of sharing and connecting provides a more holistic view of teachers' professional use of social media. Sharing and connecting are activities that may support intuitive conceptions of professional development as focused on learning. That is, teachers may be eager to share their materials so that other teachers can learn from them and connecting with other educators may provide more resources to draw from. However, Trust et al. (2016) suggests a holistic view of teacher professional development through social media that is attentive to "affective, social, cognitive, and identity aspects of teaching" (p. 16). Correspondingly, these two activities may also be understood in affective and social terms, where social media provide teachers opportunities to share stressful experiences and seek emotional support. Indeed, our examination of teachers' stress and social media use lends further weight to the emotional and social importance of social media for teachers.

\section{Limitations}

Notably, our findings focus on the social media use patterns of only 14 teachers. Although this precludes us from generalizing to a larger teacher population, our findings are 
highly granular, which enables us to understand specific patterns within teachers. Moreover, because we had collected data before the pandemic required distance learning policies, our data mirrors a natural quasi-experiment for our study sample. Thus, we can attribute changes to social media use as a function of COVID-19 related pressures. That said, our study lacked the statistical power necessary to do multi-level analysis, which would have been helpful to understand contextual features (e.g., school and district conditions). In addition, these analyses suffer from an omitted variable bias as we did not gather additional information on potentially influential variables such as classroom and school context, physiological data from teachers (e.g., did teachers or their immediate family contract the virus), or information teachers' professional learning activities outside of social media. That said, both the design of an intensive longitudinal data collection and ethical consideration for asking health-related items limited the feasibility to include such variables to this study.

\section{Future Work}

Our findings must be contextualized to teachers' reported social media use that occurred both before and after the transition to emergency remote learning. Post-Covid longitudinal studies might examine how the potential uptake of social media for professional development during Covid persists after the end of the pandemic. Such investigations would establish if social media use was ephemeral, or if it persists well after the pandemic. In a similar vein, additional work would do well to examine teachers' social media use once students have returned to the classroom and relate those patterns to reported (or observed) teaching practices, as well as student performance. Doing so would help describe the nexus of a given platform's general user affordances to its pedagogical affordances, e.g., Pinterest was used for "finding, but finding what exactly? To inform which teaching practices, if any? Qualitative work might also be used to 
examine how teachers used social media in depth; such work would help by describing the affordances and challenges that come with using social media to inform instructional practices.

\section{References}

Aguilar, S. J. (2020a). A research-based approach for evaluating resources for transitioning to teaching online. Information and Learning Sciences, 121(5-6), 301-310. https://doi.org/10.1108/ILS-04-2020-0072

Aguilar, S. J. (2020b). Guidelines and tools for bridging the digital divide. Information and Learning Sciences, 121(5-6), 285-299. https://doi.org/10.1108/ILS-04-2020-0084

Aguilar, S. J., Galperin, H., Baek, C., \& Gonzalez, E. (2020). When school comes home: How low-income families are adapting to distance learning. https://doi.org/10.35542/osf.io/su8wk

Bates, D., Mächler, M., Bolker, B., \& Walker, S. (2014). Fitting linear mixed-effects models using lme4. arXiv preprint arXiv:1406.5823.

Bruguera, C., Guitert, M., \& Romeu, T. (2019). Social media and professional development: A systematic review. Research in Learning Technology, 27. https://doi.org/10.25304/rlt.v27.2286

Bolger, N., \& Laurenceau, J. P. (2013). Intensive longitudinal methods: An introduction to diary and experience sampling research. Guilford Press.

Borko, H., Jacobs, J., \& Koellner, K. (2010). Contemporary approaches to teacher professional development. In P. Peterson, E. Baker, \& B. McGaw (Eds.), International encyclopedia of education (pp. 548e556). Oxford, UK: Elsevier 
Carpenter, J., Cassaday, A., \& Monti, S. (2018). Exploring how and why educators use Pinterest. In E. Langran, \& J. Borup (Eds.), Proceedings of Society for Information Technology \& Teacher Education International Conference. (pp. 2222-2229). Washington, DC:

Association for the Advancement of Computing in Education. Retrieved from https://www.learntechlib.org/primary/p/182833/

Carpenter, J. P., \& Green, T. D. (2017). Mobile instant messaging for professional learning: Educators' perspectives on and uses of Voxer. Teaching and Teacher Education, 68, 5367. https://doi.org/10.1016/j.tate.2017.08.008

Carpenter, J., \& Krutka, D. G. (2014). How and why educators use Twitter: A survey of the field. Journal of Research on Technology in Education, 46, 414-434. doi:10.1080/15391523.2014.925701

Carpenter, J. P., \& Krutka, D. G. (2015). Engagement through microblogging: Educator professional development via Twitter. Professional Development in Education, 41(4), 707-728. doi:10.1080/19415257.2014.939294

Carpenter, J. P., Morrison, S. A., Craft, M., Lee, M. (2020). How and why are educators using Instagram? Teaching and Teacher Education, 96, 103149. doi:10.1016/j.tate.2020.103149

Carpenter, J., Tani, T., Morrison, S., \& Keane, J. (2020). Exploring the landscape of educator professional activity on Twitter: An analysis of 16 education-related Twitter hashtags. Professional Development in Education doi:10.1080/19415257.2020.1752287

Darling-Hammond, L., Hyler, M. E., \& Gardner, M. (2017). Effective teacher professional development. Palo Alto, CA: Learning Policy Institute. 
Dede, C., \& Eisenkraft, A. (2016). Online and blended teacher learning and professional development. In C. Dede, A. Eisenkraft, K. Frumin, \& A. Hartley (Eds.), Teacher learning in the digital age: Online professional development in STEM education (pp. 112). Cambridge, MA: Harvard Education Press.

Dede, C., Jass Ketelhut, D., Whitehouse, P., Breit, L., \& McCloskey, E. M. (2009). A research agenda for online teacher professional development. Journal of Teacher Education, 60(1), 8-19. https://doi.org/10.1177/0022487108327554

Dede, C., Ketelhut, D. J., Whitehouse, P., Breit, L., \& McCloskey, E. M. (2008). A research agenda for online teacher professional development. Journal of Teacher Education, 60, 8-19. doi:10.1177/0022487108327554

Fischer, C., Fishman, B., Dede, C., Eisenkraft, E., Foster, B., Frumin, K., Lawrenz, F., Levy, A., \& McCoy, A. (2018). Investigating relationships between school context, teacher professional development, teaching practices, and student achievement in response to a nationwide science reform. Teaching and Teacher Education, 72, 107-121. https://doi.org/10.1016/j.tate.2018.02.011

Fischer, C., Fishman, B., \& Schoenebeck, S. (2019). New contexts for professional learning: Analyzing high school science teachers' engagement on Twitter. AERA Open, 5(4), 1-20. https://doi.org/10.1177/2332858419894252

Fishman, B. J., Konstantopoulos, S., Kubitskey, B. W., Vath, R., Park, G., Johnson, H., \& Edelson, D. (2014). The future of professional development will be designed, not discovered: Response to Moon, Passmore, Reiser, and Michaels, "Beyond Comparisons of Online Versus Face-to-Face PD.” Journal of Teacher Education, 65(3), 261-264. https://doi.org/10.1177/0022487113518440 
Flanigan, R. L. (2011). Professional Learning Networks Taking Off. EducationWeek. https://www.edweek.org/technology/professional-learning-networks-takingoff/2011/10?tkn=NXCFrTi53Q\%2FRNUP7oI3Dyieu\%2F9gskTJyoOc\%2F

Frumin, K., Dede, C., Fischer, C., Foster, B., Lawrenz, F., Eisenkraft, A., Fishman, B. J., Jurist Levy, A., \& McCoy, A. (2018). Adapting to large-scale changes in Advanced Placement Biology, Chemistry, and Physics: The impact of online teacher communities. International Journal of Science Education, 40(4), 397-420. https://doi.org/10.1080/09500693.2018.1424962

Fütterer, T., Hoch, E., Stürmer, K., Lachner, A., Fischer, C., \& Scheiter, K. (2021). Was bewegt Lehrpersonen während der Schulschließungen? - Eine Analyse der Kommunikation im Twitter-Lehrerzimmer über Chancen und Herausforderungen digitalen Unterrichts. Zeitschrift für Erziehungswissenschaft, 24, 443-477. https://doi.org/10.1007/s11618-02101013-8

Greene, K. (2017). Teacher blogs and education policy in a publicly private world: Filling the gap between policy and practice. Learning, Media and Technology, 42(2), 185-197. https://doi.org/10.1080/17439884.2016.1154867

Greenhalgh, S. P. (2021). Differences between teacher-focused Twitter hashtags and implications for professional development. Italian Journal of Educational Technology, 29(1), 24-43. doi:10.17471/2499-4324/1161

Greenhalgh, S. P., Rosenberg, J. M., \& Wolf, L. G. (2016). For all intents and purposes: Twitter as a foundational technology for teachers. E-Learning and Digital Media, 13, 81-98. doi:10.1177/2042753016672131 
Greenhalgh, S. P., \& Koehler, M. J. (2017). 28 days later: Twitter hashtags as "just in time" teacher professional development. TechTrends, 61, 273-281. doi:10.1007/s11528-016$0142-4$

Greenhalgh, S. P., Rosenberg, J. M., Staudt Willet, K. B., Koehler, M. J., \& Akcaoglu, M. (2020). Identifying multiple learning spaces within a single teacher-focused Twitter hashtag. Computers \& Education, 148, 103809. https://doi.org/10.1016/j.compedu.2020.103809

Greenhow, C., \& Askari, E. (2017). Learning and teaching with social network sites: A decade of research in K-12 related education. Education and Information Technologies, 22(2), 623-645. https://doi.org/10.1007/s10639-015-9446-9

Greenhow, C., \& Chapman, A. (2020). Social distancing meet social media: Digital tools for connecting students, teachers, and citizens in an emergency. Information and Learning Sciences, 121(5/6), 341-352. doi:10.1108/ILS-04-2020-0134

Greenhow, C., Galvin, S. M., Brandon, D. L., \& Askari, E. (2020). A decade of research on K-12 teaching and teacher learning with social media: Insights on the state of the field. Teachers College Record, 122(6), 1-72.

Greenhow, C. M., Staudt Willet, K. B., \& Galvin, S. (in press). Inquiring tweets want to know: \#Edchat supports for \#RemoteTeaching during COVID-19. British Journal of Educational Technology.

Greenwood, S., Perrin, A., \& Duggan, M. (2016). Social media update 2016. Pew Research Center. https://www.pewresearch.org/internet/2016/11/11/social-media-update-2016/ Gurjar, N. (2019). Connecting pre-service teachers with professional networks: Semester long use of Twitter in teacher education. In K. Graziano (Ed.), Proceedings of Society for 
Information Technology \& Teacher Education International Conference (pp. 2718-2729). Waynesville, NC: Association for the Advancement of Computing in Education Hektner, J. M., Schmidt, J. A., \& Csikszentmihalyi, M. (2007). Experience sampling method: Measuring the quality of everyday life. Sage.

Hickey, D., Duncan, J., Gaylord, C., Hitchcock, C., Itow, R. C., \& Stephens, S. E. (2020). gPortfolios: a pragmatic approach to online asynchronous assignments. Information and Learning Sciences. 121(5-6), 273-283. https://doi.org/10.1108/ILS-04-2020-0094

Hu, S., Torphy, K. T., Opperman, A., Jansen, K., \& Lo, Y.-J. (2018). What do teachers share within Socialized Knowledge Communities: A case of Pinterest. Journal of Professional Capital and Community, 3(2), 97-122. https://doi.org/10.1108/JPCC-11-2017-0025

Hur, J. W., \& Brush, T. A. (2009). Teacher participation in online communities: Why do teachers want to participate in self-generated online communities of K-12 teachers? International Society for Technology in Education, 41(3), 279-303.

Inkinen, J., Klager, C., Juuti, K., Schneider, B., Salmela-Aro, K., Krajcik, J., \& Lavonen, J.(2020). High school students' situational engagement associated with scientific practices in designed science learning situations. Science Education, 104(4), 667-692.

Kleiman, G. M., \& Wolf, M. A. (2016). Going to scale with online professional development: The Friday Institute MOOCs for Educators (MOOC-Ed) initiative. In C. Dede, A. Eisenkraft, K. Frumin, \& A. Hartley (Eds.), Teacher learning in the digital age: Online professional development in STEM education (pp. 49-68). Cambridge, MA: Harvard Education Press.

Kraut, R. E., \& Resnick, P. (2012). Building successful online communities: Evidence-based social design. MIT Press. 
Krutka, D. G., Carpenter, J. P., \& Trust, T. (2017). Enriching professional learning networks: A framework for identification, reflection, and intention. TechTrends, 61, 246-252. doi:10.1007/s11528-016-0141-5

Kyndt, E., Gijbels, D., Grosemans, I., \& Donche, V. (2016). Teachers' everyday professional development: Mapping informal learning activities, antecedents, and learning outcomes. Review of Educational Research, 86(4), 1111-1150. https://doi.org/10.3102/0034654315627864

Leeper, T. J. (2018). margins: Marginal Effects for Model Objects. (Version 0.3.23) [R package].

Liu, K., Miller, R., \& Jahng, K. E. (2016). Participatory media for teacher professional development: Toward a self-sustainable and democratic community of practice. Educational Review, 68(4), 420-443. https://doi.org/10.1080/00131911.2015.1121862

Lüdecke, D., Makowski, D., Waggoner, P., \& Patil, I. (2020). performance: Assessment of Regression Models Performance. (Version 0.4.7) [R package] doi:10.5281/zenodo.3952174

Macià, M., \& García, I. (2016). Informal online communities and networks as a source of teacher professional development: A review. Teaching and Teacher Education, 55, 291-307. doi:10.1016/j.tate.2016.01.021

MacMahon, S., Leggett, J., \& Carroll, A. (2020). Promoting individual and group regulation through social connection: strategies for remote learning. Information and Learning Sciences. 121(5-6), 285-299. https://doi.org/10.1108/ILS-04-2020-0101

Mazer, J. P., Murphy, R. E., \& Simonds, C. J. (2007). I'll see you on "Facebook": The effects of computer-mediated teacher self-disclosure on student motivation, affective learning, and 
classroom climate. Communication Education, 56, 1-17.

doi:10.1080/03634520601009710

Mercieca, B., \& Kelly, N. (2018). Early career teacher peer support through private groups in social media. Asia-Pacific Journal of Teacher Education, 46(1), 61-77. https://doi.org/10.1080/1359866X.2017.1312282

Prestridge, S. (2019). Categorising teachers' use of social media for their professional learning: A self-generating professional learning paradigm. Computers \& Education, 129, 143158. https://doi.org/10.1016/j.compedu.2018.11.003.

Raudenbush, S. W., \& Bryk, A. S. (2002). Hierarchical linear models: Applications and data analysis methods (2nd ed.). Newbury Park, CA: Sage.

Recker, M., Dorward, J., Dawson, D., Halioris, S., Liu, Y., Mao, X., . . Park, J. (2005). You can lead a horse to water: Teacher development and use of digital library resources. In Proceedings of the 5th ACM/IEEE-CS Joint Conference on Digital Libraries-JCDL '05, 1. doi:10.1145/1065385.1065387

Recker, M., Walker, A., Giersch, S., Mao, X., Halioris, S., Palmer, B., . . Robertshaw, M. B. (2007). A study of teachers' use of online learning resources to design classroom activities. New Review of Hypermedia and Multimedia, 13, 117-134. doi:10.1080/13614560701709846

Reis, H. T. (2018). Why researchers should think" real-world. A conceptual rationale. In M. R. Mehl \& T. S. Conner (Eds.), Handbook of research methods for studying daily life (pp. 323). Guilford Press.

Richter, D., Kunter, M., Klusmann, U., Lüdtke, O., \& Baumert, J. (2011). Professional development across the teaching career: Teachers' uptake of formal and informal 
learning opportunities. Teaching and Teacher Education, 27(1), 116-126.

https://doi.org/10.1016/j.tate.2010.07.008

Romero-Hall, E., Petersen, E., Sindicic, R., \& Li, L. (2020). Most versus least used social media: Undergraduate students' preferences, participation, lurking, and motivational factors. International Journal of Social Media and Interactive Learning Environments, 6(3, 244266. doi:10.1504/IJSMILE.2020.109266

Rosenberg, J. M., Greenhalgh, S. P., Koehler, M. J., Hamilton, E., \& Akcaoglu, M. (2016). An investigation of State Educational Twitter Hashtags (SETHs) as affinity spaces. ELearning and Digital Media, 13, 24-44. doi:10.1177/2042753016672351.

Rosenberg, J. M., Reid, J. W., Dyer, E., Koehler, M., Fischer, C., \& McKenna, T. J. (2020). Idle chatter or compelling conversation? The potential of the social media-based \#NGSSchat network for supporting science education reform efforts. Journal of Research in Science Teaching, 57(9), 1322-1355. https://doi.org/10.1002/tea.21660

Schmidt, J. A., Beymer, P. N., Rosenberg, J. M., Naftzger, N. N., \& Shumow, L. (2020). Experiences, activities, and personal characteristics as predictors of engagement in STEM-focused summer programs. Journal of Research in Science Teaching, 57(8), 1281-1309.

Schwarz, N. (2012). Why researchers should think "real-time": A cognitive rationale. In M. R. Mehl \& T. S. Conner (Eds.), Handbook of research methods for studying daily life (pp. 22-42). Guilford Press.

Shelton, C., Schroeder, S., \& Curcio, R. (2020). Instagramming their hearts out: What do eduinfluencers share on Instagram? Contemporary Issues in Technology and Teacher Education, 20(3), 529-554. 
Speily, O. R. B., Rezvanian, A., Ghasemzadeh, A., Saghiri, A. M., \& Vahidipour, S. M. (2020). lurkers versus posters: Investigation of the participation behaviors in online learning communities. In A. Peña-Ayala (Ed.), Educational Networking (pp. 269-298). Springer. https://doi.org/10.1007/978-3-030-29973-6_8

Staudt Willet, K. B. (2019). Revisiting how and why educators use Twitter: Tweet types and purposes in \#Edchat. Journal of Research on Technology in Education, 51, 273-289. https://doi.org/10.1080/15391523.2019.1611507

Staudt Willet, K. B., \& Carpenter, J. P. (2020). Teachers on Reddit? Exploring contributions and interactions in four teaching-related subreddits. Journal of Research on Technology in Education, 52, 216-233. https://doi.org/10.1080/15391523.2020.1722978

Staudt Willet, K. B., \& Carpenter, J. P. (2021). A tale of two subreddits: Change and continuity in teaching-related online spaces. British Journal of Educational Technology, 52(2), 714733. https://doi.org/10.1111/bjet.13051

Trust, T., Krutka, D. G., \& Carpenter, J. P. (2016). “Together we are better”: Professional learning networks for teachers. Computers \& Education, 102, 15-34. https://doi.org/10.1016/j.compedu.2016.06.007

Trust, T., Carpenter, J. P., Krutka, D. G., \& Kimmons, R. (2020). \#RemoteTeaching \& \#RemoteLearning: Educator tweeting during the COVID-19 pandemic. Journal of Technology and Teacher Education, 28(2), 151-159.

Visser, R. D., Evering, L. C., \& Barrett, D. E. (2014). \#TwitterforTeachers: The implications of Twitter as a self-directed professional development tool for $\mathrm{K}-12$ teachers. Journal of Research on Technology in Education, 46(4), 396-413.

https://doi.org/10.1080/15391523.2014.925694 
West, B. T., Welch, K. B., \& Galecki, A. T. (2014). Linear mixed models: a practical guide using statistical software. CRC Press.

Xie, K., Heddy, B. C., \& Greene, B. A. (2019). Affordances of using mobile technology to support experience-sampling method in examining college students' engagement. Computers \& Education, 128, 183-198. 


\section{Tables and Figures}

Table 1.

Platforms used to inform work as a teacher

\begin{tabular}{lrr}
\hline Platform & Number Using (\%) & Mean time (min) spent using per session $(S D)$ \\
\hline Facebook & $12(85.7 \%)$ & $28.5(23.0)$ \\
Instagram & $8(57.1 \%)$ & $17.3(18.6)$ \\
Twitter & $6(42.9 \%)$ & $10.0(19.4)$ \\
Pinterest & $6(42.9 \%)$ & $10.2(19.5)$ \\
LinkedIn & $2(14.3 \%)$ & $5.5(13.5)$ \\
Reddit & $2(14.3 \%)$ & $4.6(12)$. \\
Other & $1(7.1 \%)$ & $0.9(3.3)$ \\
Voxer & $0(0 \%)$ & $0(0)$ \\
\hline
\end{tabular}

Table 2

Proportion of Instances in Which Teachers Use Specific Platforms for Specific Purposes

\begin{tabular}{lcccccc}
\hline Platform & Finding & Sharing & Learning & Connecting & Following & Total* \\
\hline Twitter & .04 & .04 & .04 & .08 & .02 & .04 \\
Facebook & .20 & .38 & .23 & .45 & .16 & .28 \\
LinkedIn & .01 & .01 & .01 & .02 & .01 & .01 \\
Pinterest & .24 & .06 & .10 & .05 & .05 & .10 \\
Instagram & .06 & .11 & .06 & .13 & .04 & .08 \\
Reddit & .00 & .01 & .01 & .01 & .00 & .01 \\
Blogs & .31 & .19 & .30 & .22 & .22 & .25 \\
Total** & .12 & .12 & .11 & .13 & .07 & \\
\hline
\end{tabular}

*(Purpose independent from platform)

**(Platform independent from purpose) 
Table 3

Change in Teachers Use of Social Media After the COVID-19 Pandemic

\begin{tabular}{lccccccc}
\hline Effect & Unstd. B & $\boldsymbol{S E}$ & $\boldsymbol{t}$ & $\boldsymbol{p}$ & $\boldsymbol{I R R}$ & $\boldsymbol{A M E}$ & $\boldsymbol{I C C}$ \\
\hline Finding & -0.549 & 0.316 & -1.739 & 0.082 & 0.578 & -0.080 & 0.594 \\
Sharing & 2.937 & 0.416 & 7.068 & $<.001$ & 18.861 & 0.417 & 0.432 \\
Learning & 1.408 & 0.312 & 4.517 & $<.001$ & 4.089 & 0.240 & 0.400 \\
Connecting & 2.336 & 0.332 & 7.042 & $<.001$ & 10.34 & 0.394 & 0.419 \\
Following & 2.299 & 0.444 & 5.179 & $<.001$ & 9.962 & 0.256 & 0.514 \\
\hline
\end{tabular}

Note. SE stands for standard error of the estimate. IRR stands for Incident Rate Ratio. AME stands for Average Marginal Effect. ICC stands for Intraclass Correlation Coefficient.

\section{Table 4}

Effect of Teachers' COVID-related Stress Levels on Social Media Use

\begin{tabular}{lccccccc}
\hline Effect & $\boldsymbol{\beta}$ & $\boldsymbol{S E}$ & $\boldsymbol{t}$ & $\boldsymbol{p}$ & $\boldsymbol{I R R}$ & $\boldsymbol{A M E}$ & $\boldsymbol{I C C}$ \\
\hline Finding & 0.442 & 0.282 & 1.567 & 0.117 & 1.556 & 0.055 & 0.669 \\
Sharing & -0.224 & 0.245 & -0.914 & 0.361 & 0.799 & -0.034 & 0.436 \\
Learning & 0.511 & 0.28 & 1.827 & 0.068 & 1.668 & 0.066 & 0.587 \\
Connecting & -0.662 & 0.268 & -2.467 & 0.014 & 0.516 & -0.08 & 0.57 \\
Following & 0.081 & 0.238 & 0.34 & 0.734 & 1.084 & 0.011 & 0.643 \\
\hline
\end{tabular}




\section{Figure 1}

Participants' Frequency of Use of Social Media Platforms for Particular Purposes
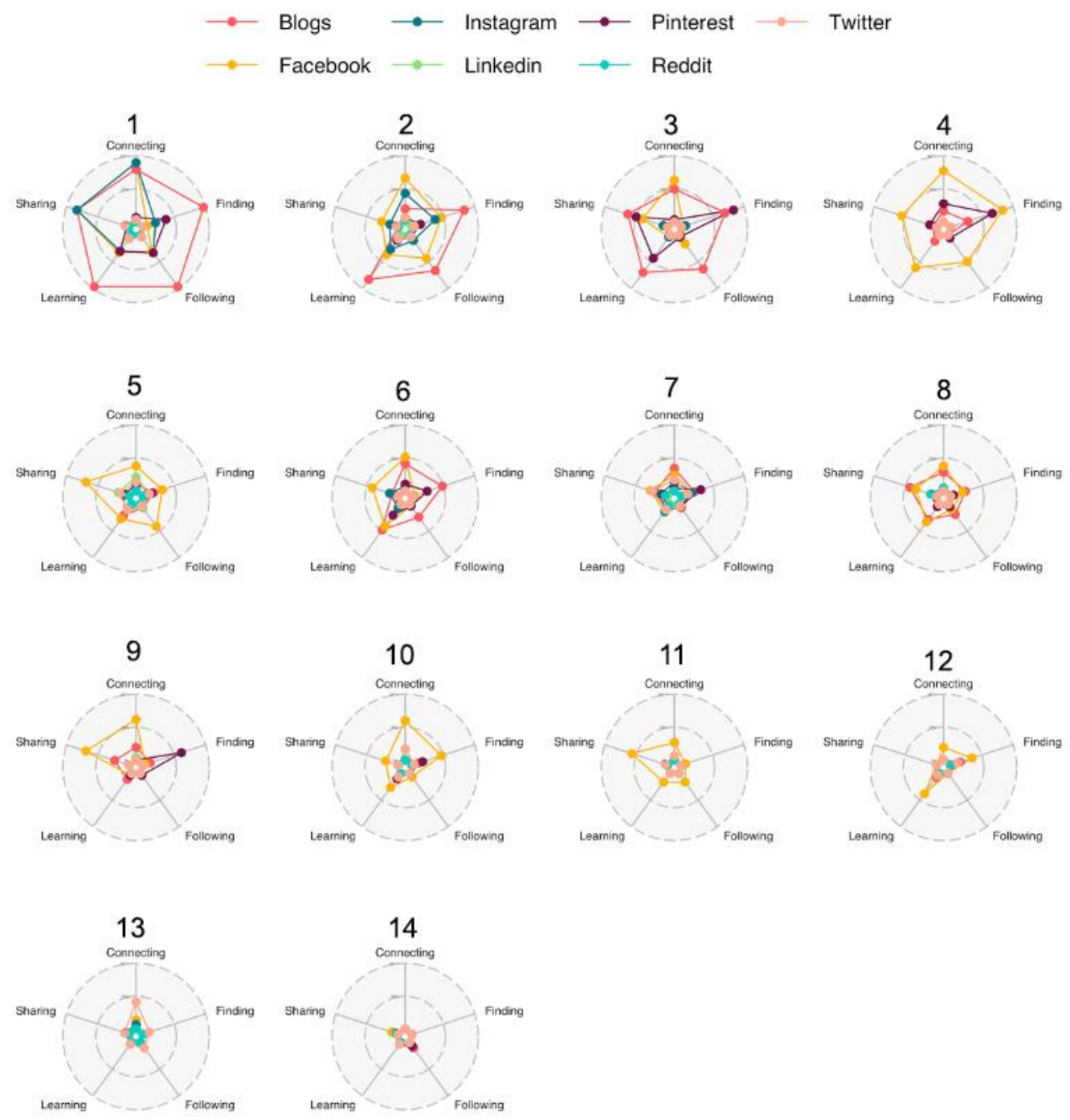

Note: The inner dotted ring represents use of a platform for a purpose in $50 \%$ of responses; the outer dotted ring represents use of a platform for a purpose in $100 \%$ of responses. 


\section{Appendix}

\begin{tabular}{|c|c|c|c|c|c|c|c|c|}
\hline effect & term & estimate & irr & ame & icc & std.error & statistic & p.value \\
\hline finding & all_mean & 0.145 & 1.157 & 0.019 & 0.642 & 0.175 & 0.83 & 0.406 \\
\hline sharing & all_mean & 0.183 & 1.201 & 0.028 & 0.448 & 0.187 & 0.982 & 0.326 \\
\hline learning & all_mean & 0.14 & 1.15 & 0.019 & 0.586 & 0.168 & 0.831 & 0.406 \\
\hline connecting & all_mean & -0.134 & 0.874 & -0.018 & 0.545 & 0.178 & -0.755 & 0.45 \\
\hline following & all_mean & 0.267 & 1.306 & 0.037 & 0.577 & 0.165 & 1.615 & 0.106 \\
\hline finding & health_mean & 0.261 & 1.298 & 0.032 & 0.667 & 0.217 & 1.199 & 0.23 \\
\hline sharing & health_mean & -0.205 & 0.815 & -0.031 & 0.442 & 0.18 & -1.142 & 0.253 \\
\hline learning & health_mean & 0.194 & 1.214 & 0.025 & 0.607 & 0.189 & 1.025 & 0.305 \\
\hline connecting & health_mean & 0.082 & 1.086 & 0.01 & 0.678 & 0.222 & 0.371 & 0.711 \\
\hline following & health_mean & 0.131 & 1.14 & 0.017 & 0.655 & 0.193 & 0.682 & 0.496 \\
\hline finding & relationships_mean & 0.194 & 1.214 & 0.024 & 0.639 & 0.186 & 1.041 & 0.298 \\
\hline sharing & relationships_mean & 0.201 & 1.223 & 0.031 & 0.437 & 0.194 & 1.038 & 0.299 \\
\hline learning & relationships_mean & 0.016 & 1.016 & 0.002 & 0.605 & 0.172 & 0.095 & 0.925 \\
\hline connecting & relationships_mean & 0.038 & 1.038 & 0.005 & 0.626 & 0.208 & 0.181 & 0.856 \\
\hline following & relationships_mean & 0.054 & 1.056 & 0.007 & 0.615 & 0.174 & 0.314 & 0.754 \\
\hline finding & tech_mean & 0.111 & 1.118 & 0.014 & 0.647 & 0.15 & 0.741 & 0.459 \\
\hline sharing & tech_mean & 0.142 & 1.153 & 0.021 & 0.435 & 0.143 & 0.996 & 0.319 \\
\hline learning & tech_mean & -0.019 & 0.981 & -0.003 & 0.598 & 0.143 & -0.132 & 0.895 \\
\hline connecting & tech_mean & -0.039 & 0.962 & -0.005 & 0.563 & 0.144 & -0.27 & 0.788 \\
\hline following & tech_mean & 0.201 & 1.223 & 0.028 & 0.584 & 0.144 & 1.397 & 0.162 \\
\hline
\end{tabular}

